\title{
Entrepreneurial Acquisitions, Open Innovation and UK High Growth SMEs
}

Suzanne Mawson and Ross Brown

Accepted for publication in Industry and Innovation

\section{FUNDING ACKNOWLEDGMENTS}

Personal acknowledgements to be added. The usual disclaimer applies. 


\begin{abstract}
This paper examines the dynamics of entrepreneurial acquisitions undertaken by UK high growth small and medium enterprises (SMEs). While entrepreneurial acquisitions are increasingly deployed by SMEs, little is known about their antecedents, motivational drivers and organisational outcomes. Drawing on detailed case study evidence from Scotland, the key factor found to be driving these acquisitions was the desire to augment and exploit technological complementarities between the acquiring and acquired firms. Acquisition can therefore be conceptualised as an advanced stage of the outside-in 'open innovation' strategies proactively used within these innovative SMEs. Firms executing this strategy typically have an acute propensity for risk, a desire for close customer engagement, effective business models and strong external orientation. The work suggests that greater attention should be paid within M\&A theory to the dynamics of these types of smaller scale entrepreneurial acquisitions.
\end{abstract}

\begin{tabular}{|c|c|c|c|}
\hline \multirow[t]{2}{*}{ Key Words: } & Entrepreneurship & High Growth Firms & Acquisition \\
\hline & Open innovation & M\&As & UK \\
\hline
\end{tabular}

JEL Classifications : D21, L0, L2, L25, L26 


\section{INTRODUCTION}

Rapid firm growth has become the focus of considerable research and debate within the entrepreneurship literature (Henrekson and Johansson, 2010; Mason and Brown, 2013; Lee, 2014). Despite over half a century of scholarly endeavour following the seminal contribution by Penrose (1959), a firm understanding of the specificities of firm growth remains elusive (Garnsey et al., 2006; Leitch et al., 2010; Wright and Stigliani, 2012). Although empirical evidence on growth is mixed (Hoffman et al., 1998), one key aspect thought to play a critical role in promoting rapid firm growth is innovation (Coad and Rao, 2008; Dobbs and Hamilton, 2007). While the precise nature of the innovation and innovation sources remains underexplored, they do appear to be more diverse and wide-ranging (Van de Vrande et al., 2009; Varis and Littunen, 2010) than scholars had previously assumed.

One key innovation input often overlooked by entrepreneurship scholars is business acquisition (Gilbert et al., 2006). This seems remiss, given the strong predilection some high growth small and medium-sized enterprises (SMEs) have for acquisition-led growth, both domestically and cross-border, especially amongst high-tech firms (Cloodt et al., 2006) and those with a high Research and Development (R\&D) intensity (Narula, 2004) seeking to undertake collaborative and 'open' innovation (Lee et al., 2010). Acquisition is often considered the domain of large conglomerate firms (King et al., 2004), while SMEs are thought to engage in organic growth (McKelvie et al. 2006). There is now, however, a growing body of evidence that indicates that acquisition is becoming increasingly commonplace in SMEs (Grimpe and Hussinger, 2008), including rapidly growing firms (McKelvie and Wiklund, 2010), with technological acquisition a 
key driver of this process (Hussinger, 2010; Arvanitis and Stucki, 2014). Despite these observations, little research has specifically examined the underlying rationale and dynamics of entrepreneurial acquisitions undertaken by rapidly growing SMEs. Indeed, only a handful of empirical studies have specifically investigated the issue of acquisitions activity and the effect of this on new venture growth (Gilbert et al., 2006), despite calls for further work on inorganic growth modes within growing firms (McKelvie and Wiklund, 2010).

This paper aims to rectify this important gap in the SME and business growth literatures by empirically examining the rationale behind entrepreneurial acquisitions made by high growth SMEs and the impact of such acquisitions. The key research question underpinning this study was "why and how do rapidly growing high tech SMEs undertake acquisition and what impact does this activity have?" Given the exploratory nature of the research, a longitudinal qualitative research design based on in-depth case studies was adopted in order to adequately address the issue of acquisition within the context of specific firms and their own unique 'internal development' and growth (Achtenhagen et al., 2010). This approach is also in line with previous work on acquisitions, where comparative case studies have been widely used to support theory building in relation to mergers and acquisitions (M\&As) (Cassiman et al., 2005; Reddy, 2015) and open innovation (Huizingh, 2011). Scotland was selected as the empirical location for this study, owing to its strong policy focus on high growth SMEs (Lee, 2014) and high growth entrepreneurship generally (Scottish Government, 2015), which has resulted in a stable population of rapidly growing and technology-based SMEs. 
The paper aims to make important theoretical and empirical contributions to the literature. First, it makes a contribution to the on open innovation literature, finding that high growth SMEs use acquisition as a key aspect of their "open" inbound innovation (Van de Vrande et al., 2009) strategies. We add to the open innovation literature by observing that acquisitions provide a key mechanism to obtain complementary technological resources from international sources, often stemming from prior relationships with acquisition targets through other external knowledge sourcing relationships. We also aim to contribute to the nascent, but as yet underdeveloped, M\&A theory on smaller scale "entrepreneurial acquisitions". This work strongly shows that being small does not preclude the use of acquisition within rapidly growth SMEs. Second, the empirical novelty of this paper is that it examined the issue of acquisition over a period of time using a longitudinal research design. This allowed us to tease out the dynamic effects of the acquisition process in SMEs, in terms of how and why rapidly growing high-tech SMEs choose to undertake acquisition and the impact of that acquisition in terms of firm operations and performance.

The paper is structured as follows. It begins with a review of the literature on acquisitions and open innovation. We then outline the methodology, before the case study findings are presented and discussed to highlight the theoretical and practical implications from the study, as well as to put forward propositions from the data. Finally, the implications of our findings for theoretical development and managerial practice are explored. 


\section{RELEVANT LITERATURE}

\subsection{M\&A Theory}

In common with strategic alliances, joint ventures and informal partnerships, M\&As have become an important sources of external growth and corporate development; a trend which has elicited a tremendous volume of literature over the last thirty years (Cartwright and Schoenberg, 2006). According to Bauer and Matzler (2014), four discernible schools of thought have emerged when analysing M\&As. First, the financial school has focused analysis on the financial performance and productivity effects of M\&As. This work has dominated the M\&A field (see King et al., 2004). Second, strategic management scholars have examined the effects of pre-merger relatedness, perceived similarities and cultural complementarity. Third, organisational scholars have examined how M\&As affect individuals, organisations as a whole and organisational culture. A final body of work has looked at the process of M\&As to examine the effectiveness and efficiency of post-merger integration and success of transactions.

Together these four theoretical lenses have dominated the busy empirical landscape within M\&A research. While space precludes a full examination of this literature, a number of scholars have highlighted various deficiencies with these analytical frameworks. According to Cartwright and Schoenberg (2006), M\&A research is strongly fragmented in scope with very little done to develop a holistic understanding of the antecedents of M\&As and their performance (Bauer and Matzler, 2014). A key criticism directed towards these approaches is their focus on specific phases of the M\&As, which prevents a more fully rounded understanding of the process from developing. Methodological constraints such as the over-emphasis on quantitative analysis 
(Graebner, 2009) coupled with a lack of longitudinal research (Cartwright and Schoenberg, 2006) have exacerbated this situation. Some authors claim that too much focus has been given to large scale M\&As within these theoretical approaches, whilst largely ignoring smaller scale acquisitions by SMEs (Weitzel and McCarthy, 2011). Clearly the dynamics of smaller scale acquisitions will depart considerably from larger scale M\&As. To overcome these limitations, a number of scholars are advocating a more integrative and nuanced understanding of the dynamics of M\&As within future empirical studies (Bauer and Matzler, 2014), together with calls for greater theoretical development on smaller scale acquisitions (Weitzel and McCarthy, 2011).

\subsection{SMEs and Open Innovation}

Overcoming the problems of resource scarcity has long been considered a core focus in startups and SMEs (Garnsey, 1998). Largely predicated on the resource-based view, which continues to be the dominant theoretical paradigm in the firm growth literature (Lockett et al., 2011: O'Cass and Sok, 2013), SMEs are considered to face resource scarcity in terms of knowledge (Grant, 1996), innovation resources and innovation capability (Sok and O'Cass, 2011). Due to this scarcity, many SMEs do not have the resources or capabilities to undertake innovation on their own. While some make do with what they have got, perhaps adopting a 'bricolage' approach (Baker et al., 2003), other small firms are faced with 'dependency' (Pfeffer and Salancik, 1978) on others for resources, particularly in terms of access to knowledge. 
To mitigate such dependency on other actors, and overcome the limitations of their lack of innovation capability and in-house 'knowledge resources' (Brunswicker and Van de Vrande, 2014), many smaller innovative firms are now engaging in 'open innovation' strategies (Van de Vrande, 2009). Defined as "the use of purposive inflows and outflows of knowledge to accelerate internal innovation" (Chesbrough et al., 2006 p. 1), an increasing number of firms are turning to open innovation as an important source of competitive advantage (West and Bogers, 2014). Felin and Zenger (2014) argue that due to the "environmental uncertainty and the complexities of innovation and knowledge recombination", increasing numbers of organisations are inclined to "interact with their environment and external stakeholders in more open ways" (p. 914).

The essence of the open innovation paradigm is that firms cannot conduct all R\&D themselves, but instead must "capitalize on external knowledge which can be licensed or bought" (Van de Vrande et al., 2009, p. 425). There are typically thought to be three main open innovation approaches - outside-in, inside-out and co-creation - with most SMEs focusing on the outside-in approach (Enkel et al., 2009) and sourcing ideas from other external organisations. While originally synonymous with larger firms like Proctor and Gamble, SMEs too are now increasingly looking outside their internal firm boundaries for sources of innovation (Gassmann et al., 2010; Brunswicker and Van de Vrande, 2014).

In order to acquire knowledge and innovation inputs, SMEs have a range of options available to them (Van de Vrande, 2013). Van de Vrande et al. (2009) conceptualise open innovation as a 
sequential process, whereby a firms start by engaging with customers and employees, as well as external networking, before moving into more 'advanced practices' like IP licensing, R\&D outsourcing and venturing. Strategic alliances have long been considered a useful co-operative mechanism for balancing knowledge sharing and autonomy (Williamson, 1991), which are important in an open innovation context. Scholars have recently sought to delineate between knowledge access and knowledge acquisition (Grant and Baden-Fuller, 2004), however, where some firms will prefer to access to a formal partner's unique knowledge resources (e.g. via strategic alliances) to complement their own, others will seeks to add to their own 'stock' of knowledge by acquiring that of their partners (Inkpen, 1998). There are a number of reasons why firms may seek to access knowledge via an alliance rather than acquisition, such as high levels of resource complementarity of two firms. Similarly, there are reasons why firms would choose acquisition e.g. resource similarity (Cassiman et al., 2005; Wang and Zajac, 2007).

Despite recognition in the literature that "acquisitions are increasingly important organizational modes for the external acquisition of technological know-how" (Vanhaverbeke, et al. 2002, p. 715), particularly for firms in smaller or developing economies (Goedhuys and Veugelers, 2012), it is a mechanism not commonly linked to the process of open innovation in SMEs. Indeed, most SMEs are thought to engage within informal open innovation activities such as employee or customer involvement (Van der Vrande, 2009; Rangus et al., 2016. Acquisitions also remain associated with large and less innovative firms (West and Bogers, 2014), which may have no choice but to acquire external technology to augment their innovation competencies. 
Therefore, analysis of acquisition within the lens of open innovation remains an underdeveloped part of the literature on how small firms expand and innovate.

\subsection{SMEs and Acquisitions}

M\&A theory is almost completely predicated on large-scale deals by large firms whereas SMEs are "broadly ignored in current research" (Bauer and Matzler, 2014). However, there seem to be a number of specific benefits to small, innovative and growth oriented firms from undertaking entrepreneurial acquisitions. Indeed, a growing body of empirical research suggests that small firms may have the capacity to outperform their larger counterparts when growing through acquisitions, especially in Europe (Weitzel and McCarthy, 2011).

First, the evidence suggests that SMEs can accrue greater benefits from acquisitions than their larger counterparts, on account of the fact that "bidder competition for SME acquisitions is less" (Hussinger 2010, p. 63). As a result, SMEs are less likely to overpay for their acquisition targets, reducing capital outlays and facilitating accrued benefits to the acquirer. Small acquisitions are also less complicated and easier to manage and integrate than acquisitions in larger firms (Hussinger, 2010; Bauer and Matzler, 2014), helping to mitigate some of the problems commonly associated with post-acquisition integration (Garrette and Dussauge, 2000). Empirical research in the US also found that "trust asymmetries" tended to be lower within small-scale acquisitions by SMEs (Graebner, 2009). Additionally, SMEs can also benefit from acquisitions in other (often unanticipated) ways, such as facilitating further technological synergies, opening up new markets and technology recombination (Graebner, 2004). Strong 
'knowledge complementarities' between a buyer and seller (Bjorkman et al., 2007) have also been found to improve the 'absorptive capacity' of the combined post-acquisition entity (Marki et al., 2010), as have previous formal alliances pre-acquisition (Balakrishnan and Koza, 1993).

There is also some emerging empirical evidence to support the longer-term benefits of acquisitions by SMEs. Indeed, recent evidence from Germany identified that SMEs use acquisitions as a mechanism to enhance their technological competences develop better customer offerings (Hussinger, 2010). Swedish SMEs were also found to positively benefit from the process of acquisition in terms of their subsequent growth (Lockett et al., 2011), while in Swiss SMEs the performance of acquiring firms post-acquisition was found to be enhanced on three important levels: sales growth, growth of value-added per employee and sales of innovative products per employee (Arvanitis and Stucki, 2014). Madhok and Keyhani (2012) found that many emerging market firms use entrepreneurial acquisitions to overcome their lack of knowledge within developed markets, supporting earlier work on the role of acquisitions by Taiwanese SMEs (Chih-Chiang, 2006).

Scholars have also found that smaller acquisitions tend to be related to technological asset formation, whereas larger acquisitions are driven by the desire to access new international markets (Grimpe and Hussinger, 2008). While 'technology buy' (Goedhuys and Veugelers, 2012) is often a crucial determinant of smaller acquisitions (Hussinger, 2010), such technological acquisitions have both potential advantages and disadvantages (Graebner, 2009; Graebner et al., 2010). Acquiring companies often view access to technology (or specialised IP) 
as a key motivation underpinning the acquisition process (Graebner, 2009; Hussinger 2010), as they seek to expedite not only product development but also facilitate customer and market engagement, which can be crucial for knowledge acquisition in SMEs (Jeppesen and Molin, 2003). The empirical evidence on benefits to acquirers from technology-driven acquisitions is, however, mixed: some studies note that the benefits are short-lived, whilst others observe more positive outcomes longer-term (Cloodt et al., 2006). The outcomes of such acquisitions may be due less to the nature of the acquisition target itself and more to the commitment and capabilities of the acquiring firm and its management team.

In sum, recent studies are beginning to illuminate our understanding on the issue of SME acquisitions, especially their importance for developing technological capabilities. Our understanding of 'why' and 'how' such acquisitions occur remains partial, however, and in need of further exploration. Typically, these types of research questions require recourse to intensive qualitative research methods such as case study analysis (Graebner et al., 2010; Easterby-Smith et al., 2015), which offer up the opportunity for important theory-building in the realm of smaller scale entrepreneurial acquisitions (see, for example, Graebner, 2009).

\section{METHODOLOGY}

\subsection{Research Approach}

In line with other inductive work on acquisitions (Graebner and Eisenhardt, 2004), a comparative case study method was chosen for this research (Eisenhardt, 1989). Case studies are considered to be an appropriate and useful method where knowledge and theory are 
underdeveloped (Eisenhardt, 1989; Yin, 2003) and are noted to be particularly relevant for exploring the complex nature of both firm growth (Eisenhardt and Martin, 2000) and the process of strategic acquisitions (Graebner, 2009). Multiple cases were selected so that accounts and data could be examined for similarities and differences across firms (Perren and Ram, 2004). A longitudinal framework was utilised to enable us to unpack the "multifaceted, temporally unfolding situations and causal mechanisms" (Graebner et al., 2012, p. 279) and to understand the issue of acquisition within each firm's own unique 'internal development' (Achtenhagen et al. 2010).

\subsection{Sampling and Data Analysis}

Firms were selected based on process of theoretical sampling (Corbin and Strauss, 1990) whereby they had to fulfil four main requirements. First, they had to be SMEs according to the OECD definition, employing between 10 and 249 employees and with revenues not exceeding $€ 50 \mathrm{~m}(\mathrm{OECD}, 2005)$ at the time of selection. Second, firms needed to be based in Scotland and be UK-based and UK-owned enterprises at the time of selection. Third, firms must have experienced a period of high growth. The OECD definition of high growth firms (henceforth HGFs) was adopted, which defines HGFs as those enterprises "with average annualised growth (in number of employees or turnover) greater than $20 \%$ per annum, over a three year period, with a minimum of 10 employees at the beginning of the growth period" (OECD 2008, p. 61). Using this (turnover) definition, the sample of HGFs was identified from the commercial database Financial Analysis Made Easy (FAME) operated by Bureau van Dijk. Fourth, the firms 
identified had to have undertaken an acquisition, which was identified through the M\&A database Zephyr (also owned by Bureau van Dijk).

Using these definitions and data sources, 353 unique Scottish firms were identified that had made one or more acquisitions during the ten-year period between 2000-2009. Crossreferencing this list of Scottish acquirers with a list of high growing firms from FAME allowed us to calculate the number of high growth SMEs in Scotland that had undertaken acquisitions. Of the 353 Scottish acquirers, nearly 50\% (176) had seen a period of high growth during the 20002009 period. HGFs who had undertaken at least one acquisition within the five years previous to the study (2005-2009) were then selected to ensure respondents could outline the rationale for the acquisition. Non-indigenous firms, firms employing more than 250 employees, and firms outside of technology based sectors were all discounted to ensure that cross-case comparability was maintained. This purposive sampling technique resulted in 13 suitable firms being identified. Five firms declined to participate in the study, leaving a final sample of eight firms. Given the sensitive nature of the issues discussed, the case study companies have been anonymised.

A number of data collection methods were used to collect both real-time and retrospective data from the eight cases. Each company was interviewed at the beginning of the study period (2009/early 2010), with 7 of them interviewed a second time in Spring 2014. Semi-structured interviews were conducted with a carefully selected member of senior management (usually the Managing Director), with questions allowing for reflection on past events, views on the 
present situation and projections for the future. Interviews were taped and transcribed directly afterwards. These firms were then 'followed' over the intervening years through secondary research, including the use of company websites, company reports, press articles, FAME and Zephyr databases. This allowed for the useful triangulation of data from the firms themselves. During the follow-up interviews, the evolutionary growth processes within the firms were explored with interviewees.

The data analysis had a number of different dimensions. All data collected was subjected to both 'within-case' and 'cross-case' analysis (Graebner, 2004; Miles and Huberman, 1994). Data was examined for key themes and patterns; it was coded into a number of a priori categories based on the literature, with new categories created for emergent issues. Formal case studies

were then prepared and firm 'fingerprints' produced in line with the work of Hagen and Zucchella (2014) for all the firms examined: mapping firm turnover changes over time, acquisition activity, critical growth triggers and key entrepreneurial events within each firm. Given space limitations, only a select number of these graphical depictions are included in our findings to illustrate key issues discussed below.

\section{COHORT CHARACTERISTICS}

While all the firms were SMEs as per the OECD definition at the beginning of the observation period, many grew beyond the technical definition during the course of the study (see Table 1 below). All were high-tech; with a number of life science $(n=3)$ and computer software related firms ( $n=4)$ within the cases, and one IT services firm. Interestingly, over two-thirds of the firms 
have been acquired themselves, either towards the end of the study $(n=2)$ or subsequently following the completion of the study in $2014(n=4)$.

Table 1. Details of Case Study Firms

\begin{tabular}{|l|c|c|c|c|}
\hline Case & Sector & Est. & Number of employees** & Turnover (fm)** \\
\hline A* & Semiconductor Design & 1984 & 410 & 110.1 \\
\hline B $^{*}$ & Optical Equipment & 1992 & 240 & 97.6 \\
\hline C & Life Science & 1995 & 300 & 105.0 \\
\hline D* & Software & 1999 & 230 & 27.2 \\
\hline E & Medical Devices & 2002 & 80 & 10.0 \\
\hline F* & Digital Media & 2001 & 246 & 64.8 \\
\hline G & Digital Media & 2005 & 430 & 80.9 \\
\hline H & Professional Services & 2005 & 500 & 57.2 \\
\hline
\end{tabular}

Source: Interviews, FAME

*Case company 'fingerprints' figures included in text.

**Turnover and employment details are for financial year ending in April 2014.

All eight firms were strongly technology-based, with knowledge (domain or proprietary) a key source of their competitive advantage. Nearly all the firms had heavily protected IP, with Company A (see Figure 1 below) registering over 60 patents in 2011 alone - almost one third (29\%) of all Scottish patents registered that year (Intellectual Property Office, 2012). However, in tandem with intra-mural R\&D, many firms derived their innovative capabilities from their links to customers and end-users. They all exhibited the traits and characteristics associated with "dynamic capabilities" (Teece, 2007), such as low levels of risk adversity, close end-user focus and the strategic use of business models.

Figure 1. Company A Performance and Development 2009-2013 


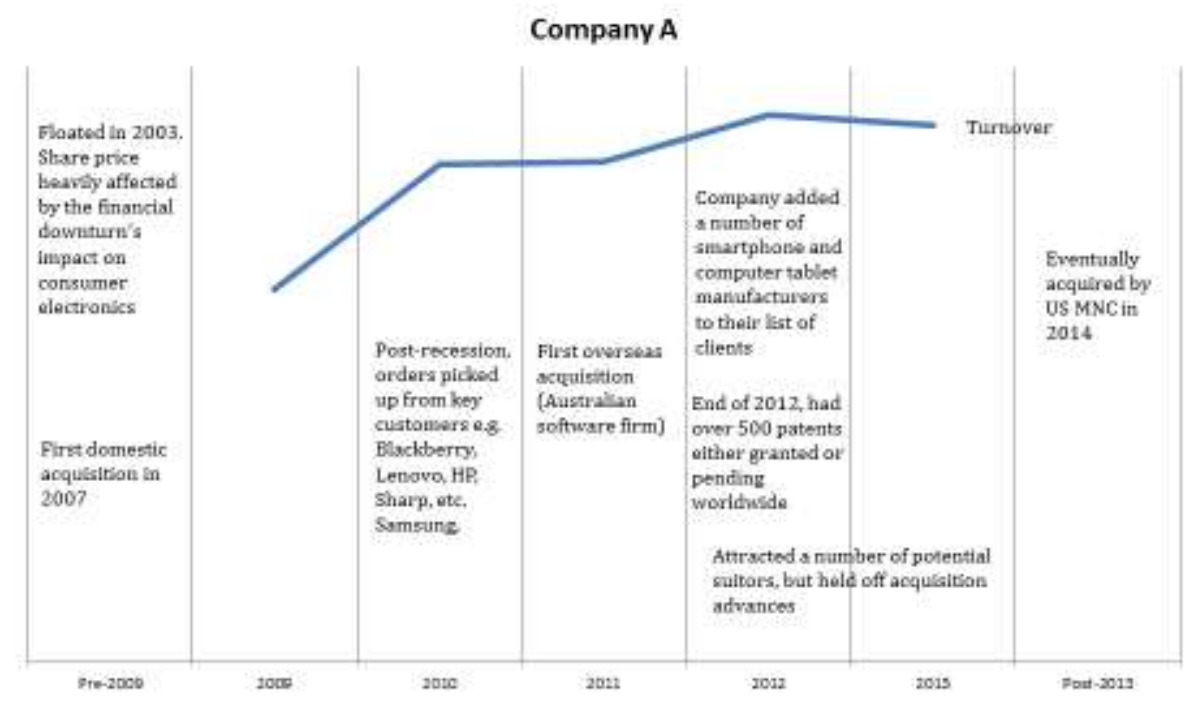

Several of the case companies had well-developed and often highly innovative business models. A good example being Company B (see Figure 2 below), an ophthalmic medical devices firm. Rather than sell their medical equipment directly to their 4,000 or so customers and end-users, a core part of their strategy was to lease their expensive equipment to their clients. In addition to receiving ongoing revenue streams from their customers as and when the equipment was used by the end-user, this business model also ensured that Company B had regular engagement with customers. This allowed for customer insights and observations to be fed back into the company (an important element of open innovation), which was critical for the ongoing development and fine tuning of equipment and other future product offerings.

Figure 2. Company B Performance and Development 2009-2013 


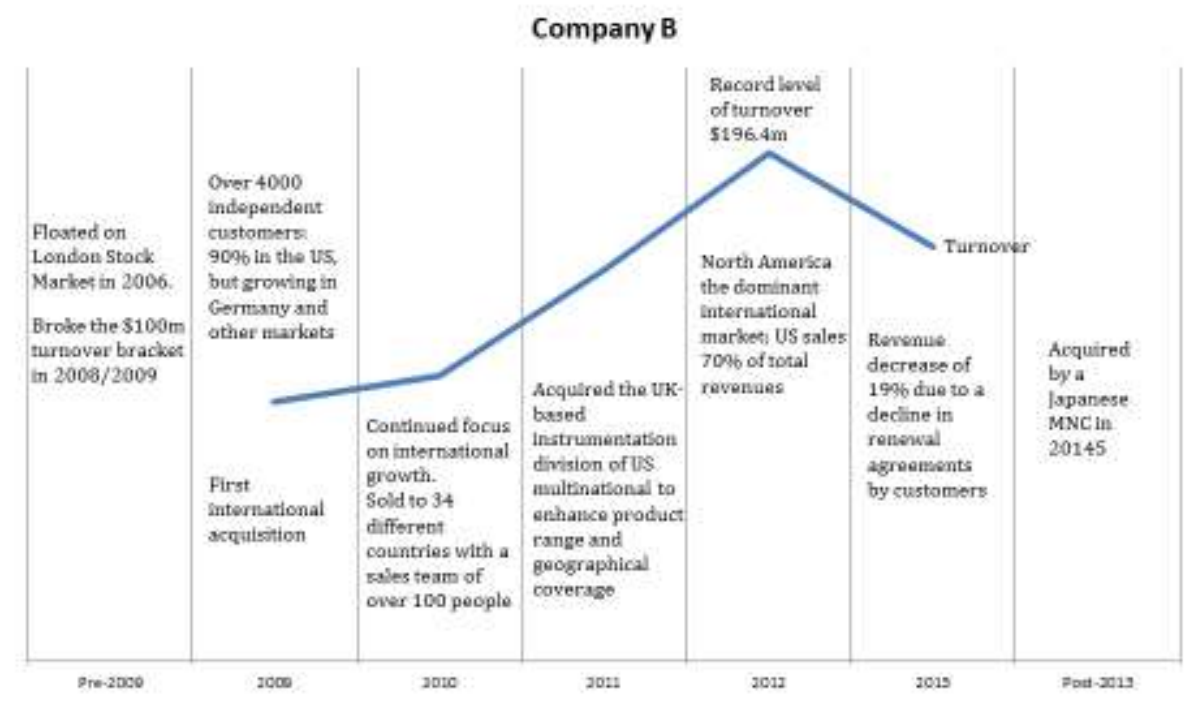

All bar two firms (Companies $G$, and F) were B2B rather than B2C ventures. Even where firms produced consumer-related products, the vast majority of their sales occurred via distributors rather than direct selling. For example, Company $C$ focused on building a European-wide distribution network via acquisition in 2009-2010. Interestingly, after Company C was acquired in late 2011, their turnover fell substantially, due in part to the divestiture of some of these previous acquisitions by the parent company.

The vast majority of the case firms were very internationally oriented (see Company $\mathrm{D}$ below as an exemplar). Nearly all of the case companies had been internationalised since inception ${ }^{1}$. As these companies matured, their reliance on international markets deepened, both in terms of overall market coverage and as a percentage of overall sales. All the case firms derived the

\footnotetext{
1 Indeed, these firms strongly resembled the "born global" stereotype depicted within the international entrepreneurship literature (Hagen and Zucchella, 2014).
} 
majority of their sales from international sources, with half of them accruing over $90 \%$ of turnover from overseas customers.

Figure 4. Company D Performance and Development 2009-2013

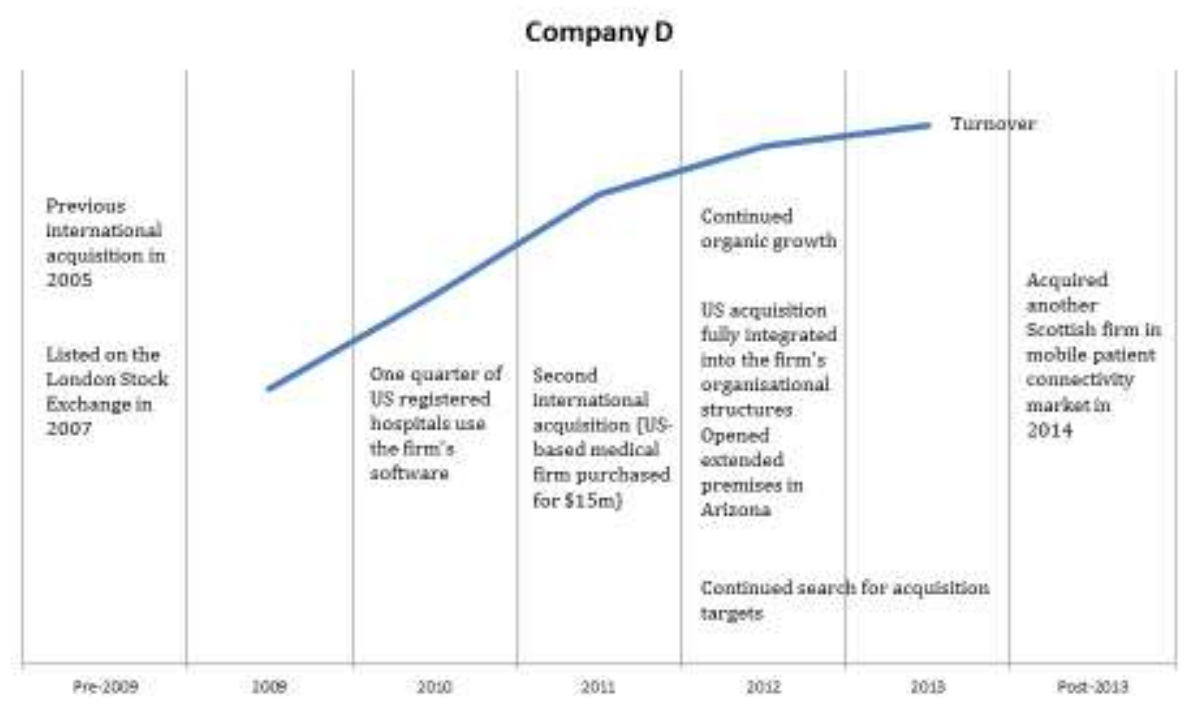

Another feature of many firms was their reliance on the internet to access customers. Both Company $F$ (Figure 6) and Company $G$ had been able to grow very rapidly by accessing a growing population of customers online. Indeed, Company F remains one of the fastest growing internet travel booking firms in the UK, owing to its ability to access a burgeoning number of customers online. The firm initially grew organically, but chose to regularly use acquisition to strategically augment its technical and operational capabilities in key areas to increase the breadth of its new product portfolio. 
Figure 6. Company F Performance and Development 2009-2013

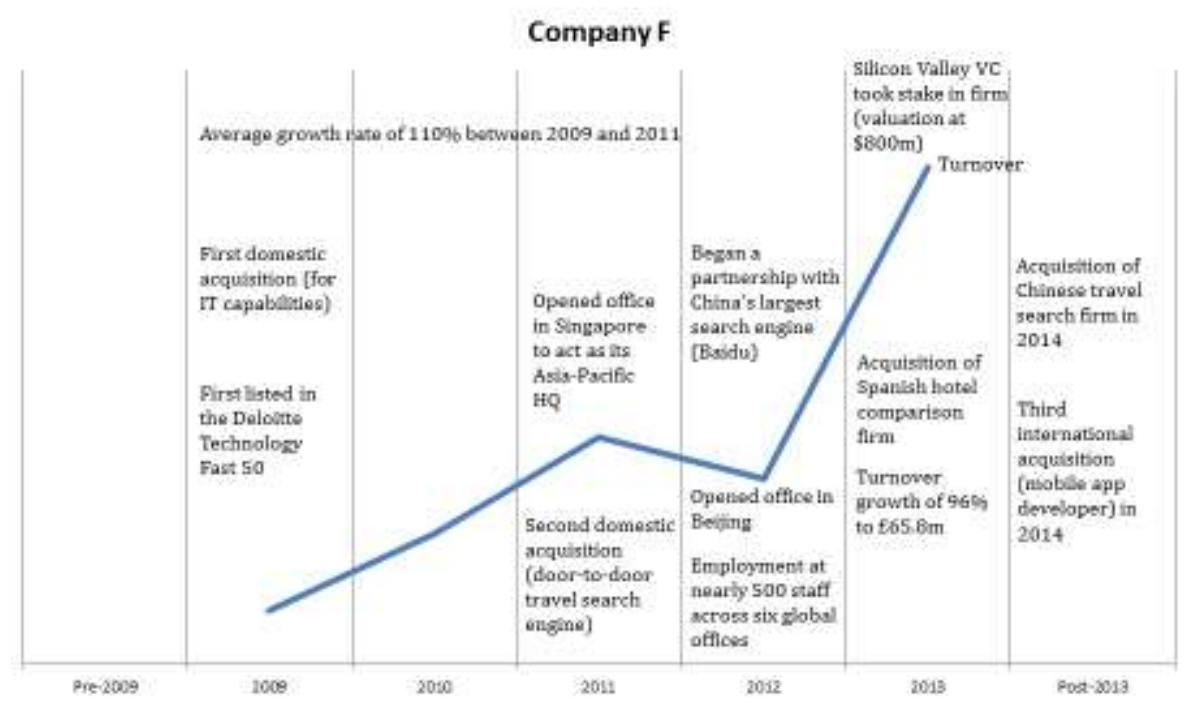

While all the case firms had grown rapidly during the study period, Company F and Company G experienced the most turbulent growth trajectories. Indeed, growth was highly discontinuous especially in companies C, F and G. Company G grew rapidly on the back of their acquisitive growth strategy. It has since experienced a major downturn in turnover, which led to a sizeable drop in turnover growth within this firm. In 2013, the company divested one of their acquired product lines, noting a lack of strategic fit.

\section{EMPIRICAL FINDINGS}

\subsection{Origins and Antecedents of Acquisition}

As shown in Table 2 below, each of the eight case study firms had acquired strategically for growth, with 7 of them acquiring internationally. Amongst our cases, acquisition, particularly 
within international markets, was an important issue to all these innovative firms. Whilst half the firms made their first acquisition ten or more years after inception, the other half acquired at a younger age, around 5 years old. This is somewhat unexpected finding, given that an acquisitive growth strategy requires both financial and managerial resources to effectively identify and integrate acquired firms. Newly established businesses often lack both.

Table 2. Acquisitions Undertaken by the Case Study SMEs

\begin{tabular}{|c|c|c|c|}
\hline Company & $\begin{array}{c}\text { \% Sales from } \\
\text { Int'I Sources }\end{array}$ & $\begin{array}{c}\text { Dates of acquisitions } \\
\text { International = (i) Domestic = (d) }\end{array}$ & $\begin{array}{c}\text { Average size band } \\
\text { of acquisition deals }\end{array}$ \\
\hline A & $80 \%$ & $2007(\mathrm{~d}) ; 2011(\mathrm{i})$ & $f 16-20 \mathrm{~m}$ \\
\hline B & $95 \%$ & $2009(\mathrm{i}) ; 2011(\mathrm{~d})$ & $f 11-15 \mathrm{~m}$ \\
\hline C & $60 \%$ & $2004(\mathrm{i}) ; 2004(\mathrm{i}) ; 2005(\mathrm{i})$ & $f 6-10 \mathrm{~m}$ \\
\hline D & $100 \%$ & $2005(\mathrm{i}) ; 2011(\mathrm{i}) ; 2014(\mathrm{~d})$ & $f 16-20 \mathrm{~m}$ \\
\hline E & $95 \%$ & $2008(\mathrm{i})$ & $f 6-10 \mathrm{~m}$ \\
\hline F & $95 \%$ & $2009(\mathrm{~d}) ; 2011(\mathrm{~d}) ; 2013(\mathrm{i}) ; 2014(\mathrm{i}) ; 2014(\mathrm{i})$ & $f 0-5 \mathrm{~m}$ \\
\hline G & $60 \%$ & $2009(\mathrm{i}) ; 2010(\mathrm{i}) ; 2010(\mathrm{i}) ; 2011(\mathrm{i}) ; 2011(\mathrm{i}) ;$ & $f 6-10 \mathrm{~m}$ \\
& & $2012(\mathrm{i}) ; 2012(\mathrm{~d})$ & \\
\hline H & $50 \%$ & $2009(\mathrm{~d}) ; 2011(\mathrm{~d})$ & $f 21-25 \mathrm{~m}$ \\
\hline
\end{tabular}

Source: Interviews; Zephyr Database

Therefore, one of the most significant findings from our research was the tendency for the case firms, irrespective of their age or size, to view acquisition as a critical part of their growth strategy. This contrasts starkly with the implicit assumption in much of the firm growth literature that young and small firms primarily look to grow organically. As company $\mathrm{H}$ emphasised: 
"We are looking at both strong, organic growth and resourceful acquisition that will complement the organic growth as well."

Somewhat counter intuitively, in the majority of cases firms acquired internationally first $(n=5)$, with a minority starting with domestic acquisitions $(n=3)$. Those firms that began with an international acquisition noted that there was little or no need for them to acquire domestically before progressing further afield. They did not feel that it was a case of "testing the waters" or "starting small", as would be expected in line with the traditional 'models' of business internationalisation ${ }^{2}$. However, a number of initial acquisitions were in neighbouring markets such as Ireland, the Netherlands and Germany; other English speaking markets with close 'psychic distance' such as Australia and the US were also prominent locations. Notably, the least internationalised firm (Company $\mathrm{H}$ ) had not acquired overseas.

The process leading up to the completion of an acquisition was more divergent across the case study firms. Pre-existing networks were found to be a contributory factor to the choice of acquisition. In a number of instances, the acquiring HGF had a previous historical relationship with the acquired firm. These pre-acquisition relationships took a variety of different forms: the firms may once have been competitors; they may have been partners on previous projects; they may have had prior R\&D licensing agreements; there may have been sales transactions between them; or one of them may have acted as a distributor for each other. Such 'courtship time' appears to have been invaluable. In the majority of cases, it was these historical

\footnotetext{
${ }^{2}$ This would seem to contradict the so-called Uppsala model which claims firms will tend to internationalise incrementally (Johanson and Vahlne, 1977).
} 
relationships and relational understandings that facilitated acquisition. The firms understood where knowledge and technology complementarities lay and subsequently sought to acquire them. The concept of partnership between the acquiring and acquired firm was a strong theme across the cases:

"We have been working in close partnership with [name of acquired company] for some time now, and the acquisition is a natural progression of that partnership"

Company A vividly demonstrated the importance of such prior relationships. Starting out as a small university spin-out in 1984, it quickly became one of Scotland's top performing technology-based firms. In 2007, it embarked on an ambitious and high-risk acquisition-led growth strategy, beginning with a major domestic acquisition designed to access new technological resources. In 2011 they acquired globally when they bought an Australian software engineering company, from which they had been licensing technology for 18 months. Given their existing relationship, Company A recognised that acquiring the Australian firm and their technology would be a good fit strategically, as it would enhance their expertise in the field of noise reduction and acoustic echo cancellation algorithms. The initial licensing agreement acted as a 'strategic platform' or 'successful first date', which formed the basis for a closer and more formal relationship between the firms.

However, in some cases, the acquiring firm had no prior knowledge of - or experience working with - the target. This was the case for Company D, who decided to buy a 'competitor' firm in 
the US so that it could augment its market position for related software and gain new technology capabilities. The target was chosen "from a distance", with decisions shaped by factors such as perceived synergy between the businesses in terms of product portfolios combined with its geographical location in a key target market of the US. These unrelated acquisitions may be more common for companies operating in the software sector, which typically require a number of complimentary products to offer distributors and customers. Based on these findings, the following propositions are suggested:

Proposition 1a: Rapidly growing high-tech SMEs tend to view acquisition as a strategic growth mode and viable alternative to organic growth.

Proposition $1 b$ : When engaging in acquisition, rapidly growing high-tech SMEs are likely to look first to acquisition targets with which they have existing relationships.

\subsection{Rationale and Dynamics of Acquisition}

The strategic rationale and decision making process underpinning these SME acquisitions was multifaceted. Singular explanations for acquisitions were rare, with rationales predicated on a complex interplay between firm (open innovation) strategy, access to technology and technological capabilities, growth ambitions, customer-pull processes and international market development. However, in the main, companies viewed acquisition as a strategic capabilities issue - a way in which to enhance their technological or service offering to customers. As 
Company A noted, their Australian acquisition greatly enhanced the firm's ability “to penetrate new customers, applications and markets". Although many acquisitions were international, the vast majority of cases viewed acquisition as a growth and technological augmentation strategy rather than an explicit 'mode of entry' into new markets. Often the issue of complementarity between the firms was key:

"We look at each potential acquisition on a number of measures. The first thing is it has to compliment the business strategy - that is obviously growth and profitability and internationalisation growth too. Second, we look at how that acquisition could benefit our current offering - we're looking for synergy"

Company E vividly illustrated the complex nature of the acquisition process. The primary motive behind Company E's US acquisition (a manufacturer of synthetic skin products) was access to materials technology to complement their own prosthetic devices. They noted that "we are acquiring further technical and competitive advantage in the prosthetics market". However, by having a direct presence in the US thanks to the acquisition, Company E was then able to develop close relationships with medical clinicians in the US. This has since enabled the firm to increase market share in the lucrative US healthcare market, a segment which now accounts for around 75 percent of the company's overall turnover. The company has recently further expanded its overseas operations, opening a new manufacturing facility in the US to increase production and facilitate significant organic growth. This strong emphasis on growth was noted in all the case companies that had acquired, including company G: 
"This acquisition provides a great opportunity for us to gain a foothold into Brazil. This is a market that we see as having strong medium to long term growth potential."

Rather than seeking greater economies of scale, which is considered a common rationale in many large-scale acquisitions such as 'roll-ups' (Risberg, 2013), resource or 'strategic complementarity' was often the ultimate goal of the acquisitions undertaken by the case firms. Looking back to Company G, while its first acquisition was influenced by the need for greater economies of scale, the company identified and acquired all its subsequent international targets to access culturally sensitive tacit knowledge that was required to grow its product offerings and market presence. This issue of complementarity was particularly true in terms of technology, where key technology and human capital was often instrumental in driving the acquisition decision-making process. This was certainly the case with Company F, who bluntly stated that "it's about technology ... and some of the talent". This corresponds with the upsurge in 'acquihires' prominent in Silicon Valley, where the acquisition of smaller companies is primarily to gain access to human capital within start-ups (Chatterji and Patro, 2014).

Most of the cases reveal similarly strong levels of firm-level 'opportunity-recognition' and risktaking when executing acquisitions of complementary technology or resources. This was certainly the case with Company F, who evaluated their acquisition targets on the basis of strategic fit, internal capabilities, and whether these targets were primed for development and able "to take it to the next level". Given that the strategic fit between an acquiring firm and 
their proposed acquisition target was paramount, technology often weighed heavily in the decision making process. For example, Company F, a rapidly growing web-based travel firm, sought to augment their customer offering to include hotels as well as providing other accommodation services. The issue of 'speed' was important and, although the firm admitted they could easily build up their own internal capabilities in this area, they believed the quicker (and more efficient) route was to acquire. Company F subsequently acquired a Spanish hotel internet search firm in 2013 to get "velocity" into their accommodation offering. This leads us to posit the following propositions:

Proposition 2a: Rapidly growing high-tech SMEs tend to use acquisitions as a way to build their technological capabilities, looking predominantly for resource complementarity rather than similarity.

Proposition 2b: Acquisition can be successfully utilised as part of the in-bound open innovation strategies of rapidly growing high-tech SMEs.

\subsection{Performance Post-Acquisition}

Owing to the longitudinal nature of the fieldwork undertaken, the research was able to track the impact of acquisitions on acquiring firm development and financial performance (turnover). Within the cases, it appeared that the performance of the newly acquired businesses had been beneficial for the acquiring SMEs. In all but one of the cases, strong growth and performance had continued post-acquisition. One firm noted: 
"Everything we had envisaged from the acquisition has come to fruition in less than a year. We have successfully integrated [name of acquiring company], increased our recurring income streams and we have already expanded customer relationships to benefit from our new service offering."

The majority of the cases revealed the dynamic and cumulative nature of the benefits which had arisen from undertaking these acquisitions. They all perceived acquisition as a natural part of their firms' evolution, which could help augment or 'skip' hurdles in their organic growth processes. Firms sensed that strong strategic opportunities could arise from acquisitions, which were often dynamic in nature rather than purely the addition of new 'resources'. Again, the desire to capitalise on technological synergies between the firms was a key motivational driver, as eloquently articulated by Company $\mathrm{H}$ :

"For example, for our most recent acquisition we had this technology, they had that technology, and if you brought the two together $1+1=3$. This actually gave us a heck of a lot more than we had if we just had those bits independently. It depends, but we are usually looking for alchemy off the back of our acquisitions and usually looking for something to be a lot more than what it was."

In none of the cases had the firms explicitly encountered significant problems integrating their acquisitions into their existing organisational structures, although this appears to be strongly 
influenced by prior managerial experience of M\&A activity. It appears that the predilection for acquisitions is helped by prior-experience. For example, Company $\mathrm{H}$ was very quick to acknowledge that cumulative experiential knowledge assists with post-acquisition integration:

"We are helped by the fact that quite a number of us have been involved in mergers and acquisitions before. So it wouldn't have been the first time we have done a deal, done a transition and brought people into the business. We probably made all the mistakes before and learned from those and have been able to make the best use of those to bring about fairly smooth transitions."

While some case companies did utilise a number of the integration 'tools' seen in larger acquisitions (e.g. the use of an temporary integration 'managers'), most firms ceded considerable autonomy to their 'new' operations. Indeed, rather than becoming absorbed within the acquiring firm's operations, in most of the cases the acquired firms retained their former identity and remained as autonomous entrepreneurial subsidiaries rather than becoming mere "branch plants" of the home firms. As one executive from Company F noted, "we just let them get on with it". This contrasts with larger acquisitions, which often require significant levels of post-acquisition integration. Thereby we propose:

Proposition 3a: Rapidly growing high-tech SMEs tend to see rapid financial benefits from acquisitions in terms of positive changes to turnover. 
Proposition 3b: The successful completion of acquisitions by rapidly growing high-tech SMEs tends to be strongly influenced by prior management experience of M\&A activity.

\section{DISCUSSION}

The rich empirical findings reported provide important insights into the dynamics of acquisition within this small cohort of dynamic rapidly growing high-tech SMEs, enabling an important contribution to be made to theoretical development on acquisition as an inorganic growth mode and conduit for open innovation (Gilbert et al., 2006; McKelvie and Wiklund, 2010). In terms of M\&A theory, the findings suggest that entrepreneurial acquisitions are now a core strategy for rapidly growing internationally focused high-tech SMEs.

As discussed, a key finding from the data was the fact that the rapidly growing high-tech SMEs in our sample viewed acquisition as a strategic growth mode and viable alternative to organic growth (Proposition 1a), rather than as something limited to larger organisations. Whilst the SME literature continues to implicitly assume that SMEs prefer to grow organically, our data supports the observation by other scholars that acquisition is becoming increasingly commonplace in SMEs (Grimpe and Hussinger, 2008), particularly those experiencing (or aiming for) rapid growth (McKelvie and Wiklund, 2010). This is at odds with other work on high growth SMEs in Cambridge, which noted a preference for alliances rather than acquisitions (Mohr et al., 2013). 
The firms examined in our sample also saw clear, often immediate, financial benefits from acquisitions in terms of their turnover (Proposition 3a). This confirms other recent work showing that SMEs are more effective at executing acquisitions than larger firms (Weitzel and McCarthy, 2011). Further research is needed on larger and more diverse samples to determine whether this focus on inorganic growth holds amongst different SME cohorts and if there is variation in terms of the financial benefits.

Linked with the issue of growth mode, acquisition was found to be an important aspect of the innovation strategies within these firms, as they sought to build their technological capabilities (Proposition 2a). Whilst the combination of two firms could perhaps be viewed as a source of 'internal' or 'closed' rather than 'open' innovation, the fact that the knowledge generated remained outside the immediate domain of the acquiring firm means that acquisitions can also be classified as an 'advanced practice' within the spectrum of open innovation (Van de Vrande et al. 2009). Acquisitions, however, clearly throw up a "grey" area between purely open and closed innovation (Barge-Gil, 2010), as the organisational boundaries between firms become less clearly delineated through acquisitions (as well as alliances and joint ventures).

Interestingly, the firms in our sample emphasised the importance of resource complementarity when undertaking an acquisition. This is at odds with much of the wider M\&A literature, which notes that resource complementarity is more likely to be a driver of alliances than acquisition (Wang and Zajac, 2007) and that acquisitions based on complementarity have a much higher failure rate (Garrette and Dussauge, 2000). Much of this literature focuses on larger firms, so 
more research is needed to further explore these issues within the SME context (Proposition $2 b)$.

In line with the wider M\&A literature, pre-existing relationships (Porrini, 2004; Wang and Zajac, 2007; Chang and Tsai, 2013) appeared to be a strong driver for instigating and cementing the acquisition process within our sample (Proposition 1b). When previous connections exist between firms, it appears to reduce the level of informational and trust asymmetries (Graebner, 2009), mitigating the risk levels associated with the acquisition. Knowledge of the acquisition target's "track record" therefore helps to alleviate the 'agency' problems when seeking a suitable acquisition target. This confirms the importance of pre-existing networks for SMEs coupled with the relational, as opposed to a "spot market", nature of these types of acquisitions. The fact that many of the case study firms acquired internationally first, before undertaking domestic acquisitions, was unexpected. The wider literature notes that that international acquisitions of previously 'allied firms' show significantly better returns than domestic acquisitions (Zaheer et al., 2010), which may in part account for this finding.

Interestingly, these acquisitions acted as an important - if sometimes unplanned - conduit into overseas markets, opening up opportunities for further international expansion. These acquisitive growth-oriented SMEs are akin to the 'buy globals' noted by other scholars (Brown and Mawson, 2016), on account of their acquisitive international growth strategies. In some instances, involvement in other markets had additional in-bound innovation advantages for firms, such as fostering closer end-user or customer engagement, thus facilitating further 
international sales. Further work exploring international vs. domestic acquisition and its effects on SMEs specifically is needed, particularly in terms of unpacking the issue of prior relationships.

As one might expect, as firms pursued acquisitive growth they became increasingly committed to undertaking further strategic acquisitions. This suggests that there is a cumulative logic to growth through acquisition, with prior experience playing an important mediating role (Proposition 3b). This reinforces observations from the wider M\&A literature that prior acquisition experience equips firms with key skills and capabilities that facilitate further acquisition (Wang and Zajac, 2007). This helps to explain why a number of firms in our sample became 'serial acquirers' during the study period.

Due to the limited time span of the research, however, neither the long-term effects of acquisition dynamics nor the effectiveness of the innovation processes in the combined entities could be fully explored. A number of factors suggest, however, that the chances of postacquisition success are positive. Acquisitions in SMEs often represent new combinative capabilities, rather than the 'more of the same' found in larger-scale related corporate acquisitions. In many cases, SMEs do not wish to integrate the newly acquired firms within their own structures, as evident within the cases reported, which is likely to reduce the coordination-autonomy dilemma. Therefore, the small scale of the acquired firms makes the managerial 'digestibility' less problematic (Vanhaverbeke et al., 2002) than it would be in larger organisations. 


\section{CONCLUSIONS}

This exploratory study serves as an important corrective to the lack of work in the literature examining acquisitions by high growth SMEs. The propositions outlined lay the groundwork for future theoretical development on the innovative dynamics of SME acquisitions. Overall, the work strongly suggests that M\&A theory needs to pay much greater attention to the dynamics of entrepreneurial acquisitions within rapidly growing firms. Entrepreneurship scholars in particular have been slow to examine this issue empirically or conceptually. However, from this evidence we postulate that acquisitions can legitimately be viewed as an "act and form of entrepreneurship" (Madhok and Keyhani, 2012, p 38).

The paper's novel empirical findings also make a theoretical contribution to the literature on SME growth and open innovation. Empirically we found that access to knowledge was at the heart of these entrepreneurial acquisitions. They provide a key mechanism to obtain complementary knowledge resources from international sources, often stemming from prior relationships with acquisition targets through other external knowledge sourcing relationships. Acquisition can therefore be conceptualised as an advanced stage of the outside-in 'open innovation' strategies proactively used within these innovative SMEs. These open innovation processes are a highly complex, relational and path dependent processes where past relationships often shape and mediate the acquisition process. Acquisitions in turn allowed for the co-creation of new firm-specific assets and capabilities such as access to new technology, access to specialist sources of human capital or a closer proximity to overseas customers. It appears that the combinative synergies (i.e. the notion of $1+1=3$ ) from acquisition augments 
the dynamic capabilities of the newly created entities which are assembled from these interfirm combinations.

The study has obvious limitations opening up avenues for further research. Drawing on a very small sample of firms within a single geographical location means these findings remain heavily context specific. Further work is needed to explore the nature of acquisitive growth in larger populations of SMEs in different geographical contexts. Furthermore, far from being a representative sample, the cases examined are arguably some of the most dynamic, rapidly growing and highly internationalised SMEs in the UK. It appears therefore, that only firms with strong dynamic capabilities are able to execute these complex acquisitions. More work is needed to investigate the nature and efficacy of the acquisition process in less rapidly growing SMEs. And finally, closer scrutiny needs to be paid to the longer-term effectiveness of technology acquisitions within open innovation strategies and how SMEs manage their inbound innovation processes post-acquisition. Hopefully, unravelling further the complex processes and dynamics of entrepreneurial acquisitions can become an emerging strand within the evolving literature on open innovation and firm growth. 


\section{REFERENCES}

Achtenhagen, L., Naldi, L. and Melin, L. (2010) "Business Growth" - Do Practitioners and Scholars Really Talk About the Same Thing? Entrepreneurship Theory and Practice 34(2): 289316.

Arvanitis, S. and Stucki, T. (2014) Do mergers and acquisitions among small and medium-sized enterprises affect the performance of acquiring firms? International Small Business Journal, 33(7): 752-773.

Baker, T., Miner, A. S. and Eesley, D. T. (2003) Improvising firms: Bricolage, account giving and improvisational competencies in the founding process. Research policy, 32(2): 255-276.

Balakrishnan, S. and Koza, M. P. (1993) Information asymmetry, adverse selection and joint ventures. Journal of Economic Behavior and Organization, 20: 99-117.

Barge-Gil, A. (2010) Open, semi-open and closed innovators: towards an explanation of degree of openness. Industry and innovation, 17(6): 577-607.

Bauer, F. and Matzler, K. (2014) Antecedents of M\&A success: The role of strategic complementarity, cultural fit, and degree and speed of integration. Strategic Management Journal, 35(2): 269-291.

Bjorkman, I., Stahl, K. and Vaara, E. (2007) Cultural differences and capability transfer in crossborder acquisitions: the mediating roles of capability complementarity, absorptive capacity and social integration. Journal of International Business Studies, 38: 658-672.

Brown, R. and Mawson, S. (2016) The Geography of Job Creation in High Growth Firms: The Implications of 'Growing Abroad'. Environment and Planning C: Government and Policy, 34: 207-227.

Brunswicker, S. and Van de Vrande, V. (2014) 'Exploring Open Innovation in Small and MediumSized Enterprises'. In: Chesbrough, H., Vanhaverbeke, W., West, J. (eds New Frontiers in Open Innovation. Oxford: Oxford University Press, pp. 135-156.

Cartwright, S. and Schoenberg, R. (2006) Thirty years of mergers and acquisitions research: Recent advances and future opportunities. British Journal of Management, 17(S1): S1-S5.

Cassiman, B., Colombo, M. G., Garrone, P. and Veugelers, R. (2005) The impact of M\&A on the R\&D process: An empirical analysis of the role of technological-and market-relatedness. Research Policy, 34(2): 195-220.

Chang, S-C. and Tsai, M-T. (2013) The effect of prior alliance experience on acquisition performance. Applied Economics, 45(6): 765-773.

Chatterji, A. and Patro, A. (2014) Dynamic capabilities and managing human capital. The Academy of Management Perspectives, 28(4): 395-408. 
Chesbrough, H. W. (2003) Open innovation: The new imperative for creating and profiting from technology. Harvard Business Press.

Chesbrough, H., Vanhaverbeke, W. and West, J. (Eds.). (2006) Open innovation: Researching a new paradigm. Oxford: Oxford University Press.

Chih-Chiang, Lu. (2006) Growth strategies and merger patterns among small and medium-sized enterprises: an empirical study. International Journal of Management 23, no. 3 (2006): 529.

Cloodt, M., Hagedoorn, J. and Kranenburg, H. (2006) Mergers and acquisitions: Their effect on the performance of companies in high tech industries. Research Policy 35: 642-654.

Coad, A., \& Rao, R. (2008). Innovation and firm growth in high-tech sectors: A quantile regression approach. Research policy, 37(4), 633-648.

Corbin, J. and Strauss, A. (1990) Grounded theory research: Procedures, canons, and evaluative criteria. Qualitative Sociology, 13(1): 3-21.

Dobbs, M. and Hamilton, R. T. (2007) Small business growth: recent evidence and new directions, International Journal of Entrepreneurial Behavior \& Research, 13(5): 296 - 322.

Easterby-Smith, M., Thorpe, R. and Jackson, P. (2015) Management and business research. 5th ed. Sage Publications, London.

Eisenhardt, K. (1989) Building Theories from Case Study Research. Academy of Management Reivew, 14(4): 532-550.

Eisenhardt, K. and Martin, J. (2000) Dynamic capabilities: what are they?. Strategic Management Journal, 21: 1105-1121.

Enkel, E., Gassmann, O. and Chesbrough, H. W. (2009) Open R\&D and open innovation: Exploring the phenomenon. $R$ \& D Management, 39(4), 311-316

Felin, T. and Zenger, T. R. (2014) Closed or open innovation? Problem solving and the governance choice. Research Policy, 43(5) : 914-925.

Garnsey, E. (1998). A theory of the early growth of the firm. Industrial and corporate change, 7: 523-556.

Garnsey, E., Stam, E. and Heffernan, P. (2006) New firm growth: Exploring processes and paths. Industry and Innovation, 13: 1-20.

Garrette, B. and Dussauge, P. (2000) Alliances versus acquisitions: Choosing the right option. European Management Journal, 18(1): 63-69.

Gassmann, O., Enkel, E. and Chesbrough, H. (2010) The future of open innovation. R\&D Management, 40(3), 213-221. 
Gilbert, B., McDougall, P. and Audretsch, D. (2006) New venture growth: A review and extension. Journal of Management, 25: 751-778.

Goedhuys, M. and Veugelers, R. (2012) Innovation strategies, process and product innovations and growth: Firm-level evidence from Brazil. Structural Change and Economic Dynamics, 23(4): 516-529.

Graebner, M. (2004) Momentum and serendipity: How acquired leaders create value in the integration of technology firms. Strategic Management Journal, 25: 751-777.

Graebner, M. (2009) Caveat venditor: Trust asymmetries in acquisitions of entrepreneurial firms. Academy of Management Journal, 52(3): 435-472.

Graebner, M. E. and Eisenhardt, K. M. (2004) The seller's side of the story: Acquisition as courtship and governance as syndicate in entrepreneurial firms. Administrative Science Quarterly, 49(3): 366-403.

Graebner, M. E., Eisenhardt, K. M. and Roundy, P. T. (2010) Success and Failure in Technology Acquisitions: Lessons for Buyers and Sellers, Academy of Management Perspectives, 24(3): 7392.

Graebner, M. E., Martin, J. A. and Roundy, P. T. (2012) Qualitative data: Cooking without a recipe. Strategic Orientation, 10: pp. 276-284.

Grant, R. M. (1996) Toward a knowledge-based theory of the firm. Strategic Management Journal, 17: 109-122.

Grant, R. M. and Baden-Fuller, C. (2004) A Knowledge accessing Theory of Strategic Alliances. Journal of Management Studies, 41: 61-84.

Grimpe, C. and Hussinger, K. (2008) Market and technology access through firm acquisitions: Beyond one size fits all. New Perspectives in International Business Research, 3: 289.

Hagen, B. and Zucchella, A. (2014) Born Global or Born to Run? The Long-Term Growth of Born Global Firms. Management International Review, 54: 497-525.

Henrekson, M. and Johansson, D. (2010) Gazelles as job creators: a survey and interpretation of the ecidence. Small Business Economics, 35(2): 227-244.

Hoffman, K., Parejo, M., Bessant, J. and Perren, L. (1998) Small firms, R\&D, technology and innovation in the UK: a literature review. Technovation, 18(1): 39-55.

Huizingh, E. K. R. E. (2011) Open Innovation: State of the art and future perspectives. Technovation 31: 2-9.

Hussinger, K. (2010) On the importance of technological relatedness: SMEs versus large acquisition targets. Technovation, 30: 57-64. 
Inkpen, A. C. (1998) Learning and knowledge acquisition through international strategic alliances. Academy of Management Executive, 12(4): 69-80.

Jeppesen, L. B. and Molin, M. J. (2003) Consumers as co-developers: Learning and innovation outside the firm. Technology Analysis \& Strategic Management, 15(3): 363-383.

Johanson, J. and Vahlne, J. (1977) The Internationalisation Process of the firm - A model of Knowledge Development and Increasing Foreign Market Commitment. Journal of International Business Studies, 8: 23-32.

King, D., Dalton, D., Daily, C. and Covin, J. (2004) Meta-Analyses of Post-Acquisition Performance: Indicators of Unidentified Moderators. Strategic Management Journal, 25: 187200.

Lee, N. (2014) What holds back high-growth firms? Evidence from UK SMEs. Small Business Economics, 43(1): 183-195.

Lee, S., Park, G., Yoon, B. and Park, J. (2010) Open innovation in SMEs - An intermediated network model. Research Policy 39: 290-300.

Leitch, C., Hill, F. and Neergaard, H. (2010) Entrepreneurial and Business Growth and the Quest for a "Comprehensive Theory": Tilting at Windmills?. Entrepreneurship Theory and Practice, 34(2): 249-260.

Lockett, A., Wiklund, J., Davidsson, P. and Girma, S. (2011) Organic and Acquisitive Growth: Reexamining Testing and Extending Penrose's Growth Theory. Journal of Management Studies, 48: 48-74.

Madhok, A. and Keyhani, M. (2012) Acquisitions as entrepreneurship: asymmetries, opportunities, and the internationalization of multinationals from emerging economies. Global Strategy Journal, 2(1): 26-40.

Marki, M., Hitt, M. and Lane, P. (2010) Complementary technologies, knowledge relatedness, and invention outcomes in high technology mergers and acquisitions. Strategic Management Journal, 31: 602-628.

Mason, C., \& Brown, R. (2013) Creating good public policy to support high-growth firms. Small Business Economics, 40(2), 211-225.

McKelvie, A. and Wiklund, J. (2010) Advancing Firm Growth Research: A Focus on Growth Mode Instead of Growth Rate. Entrepreneurship Theory \& Practice, 34: 261-288.

McKelvie, A., Wiklund, J. and Davidsson, P. (2006) "A resource-based view of organic and acquired growth." In J. Wiklund, D. Dimov, J. Katz and D.Shepherd (Eds.) Advances in entrepreneurship, firm emergence, and growth, Vol. 9, Entrepreneurship: Frameworks and empirical investigations from forthcoming leaders in European research, pp. 179-199, Elseveir, Amsterdam. 
Miles, N. and Huberman, A. (1994) Qualitative Data Analysis: A Sourcebook of New Methods ( $2^{\text {nd }}$ Ed.). London: Sage.

Mohr, V., Garnsey, E. and Theyel, G. (2013) The role of alliances in the early development of high-growth firms. Industrial and Corporate Change, 23(1): 233-259.

Narula, R. (2004) R\&D collaboration by SMEs: new opportunities and limitations in the face of globalisation. Technovation 24(2): 153-161.

O'Cass, A. and Sok, P. (2013) The role of intellectual resources, product innovation capability, reputational resources and marketing capability combinations in firm growth. International Small Business Journal, 32(8): 996-1018.

OECD (2005) OECD SME and Entrepreneurship Outlook: 2005. Paris: OECD.

OECD (2008) Measuring Entrepreneurship: A Digest of Indicators. OECD-Eurostat Entrepreneurship Indicators Program. Paris: OECD.

Penrose, E. (1959) The Theory of the Growth of the Firm, First Edition, Oxford: Basil Blackwell.

Perren, L. and Ram, M. (2004) Case-study method in small business and entrepreneurial research Mapping boundaries and perspectives. International Small Business Journal, 22(1): 83101.

Pfeffer, J. and Salancik, G. R. (1978) The External Control of Organisations: A Resource Dependence Perspective, New York: Harper \& Row.

Porrini, P. (2004) Can a Previous Alliance Between an Acquirer and a Target Affect Acquisition Performance? Journal of Management, 30(4): 545-562.

Rangus, K., Drnovšek, M. and Di Minin, A. (2016) Proclivity for open innovation: Construct development and empirical validation. Innovation, 18(2): 191-211.

Reddy, K. S. (2015) The state of case study approach in mergers and acquisitions literature: A bibliometric analysis. Future Business 1: 13-34.

Risberg, A. (Ed.). (2013). Mergers \& Acquisitions: A Critical Reader. London: Routledge.

Scottish Government (2015) Scotland's Economic Strategy March 2015, Scottish Government, Edinburgh. Download from: http://www.gov.scot/Resource/0047/00472389.pdf

Sok, P. and O'Cass, A. (2011) Achieving superior innovation-based performance outcomes in SMEs through innovation resource-capability complementarity. Industrial Marketing Management, 40(8): 1285-1293.

Teece, D. (2007) Explicating Dynamic Capabilities: The Nature and Microfoundations of (Sustainable) Enterprise Performance. Strategic Management Journal, 28: 1319-1350. 
Van de Vrande, V. (2013) Balancing your technology-sourcing portfolio: How sourcing mode diversity enhances innovative performance. Strategic Management Journal, 34(5): 610-621.

Van de Vrande, V., de Jong, J. P. J., Vanhaverbeke, W. and de Rochemont, M. (2009) Open innovation in SMEs: trends, motives and management challenges. Technovation, 29: 423-437.

Vanhaverbeke, W., Duysters, G., and Noorderhaven, N. (2002) External technology sourcing through alliances or acquisitions: An analysis of the application-specific integrated circuits industry. Organization Science, 13(6), 714-733.

Varis, M. and Littunen, H. (2010). Types of innovation, sources of information and performance in entrepreneurial SMEs. European Journal of Innovation Management, 13(2): 128-154.

Wang, L. and Zajac, E. J. (2007) Alliance or acquisition? a dyadic perspective on interfirm resource combinations. Strategic Management Journal, 28(13): 1291-1317.

Weitzel, U. and McCarthy, K. J. (2011). Theory and evidence on mergers and acquisitions by small and medium enterprises. International Journal of Entrepreneurship and Innovation Management, 14(2-3): 248-275.

West, J. and Bogers, M. (2014). Leveraging external sources of innovation: a review of research on open innovation. Journal of Product Innovation Management, 31: 814-831.

Williamson, O. E. (1991) Comparative economic organisation: the analysis of discrete structural alternatives. Administrative Science Quarterly, 36: 269-296.

Wright, M. and Stigliani, I. (2012) Entrepreneurship and Growth. International Small Business Journal, 31: 3-22.

Yin, R. K. (2003) Case Study Research Design and Methods (3rd ed.). Thousand Oaks, CA: Sage Publications.

Zaheer, A., Hernandez, E. and Banerjee, S. (2010) Prior Alliances with Targets and Acquisition Performance in Knowledge-Intensive Industries. Organization Science, 21(5): 1072-1091. 